\title{
Prime factors of Vendor Selection for Indian Telecom Service Provider for effective SCM:A Factor Analysis using Centroid Method
}

\author{
Mr.Smrutiranjan Mohanty ${ }^{1}$, Dr.Balaji M.Dabade ${ }^{2}$ \\ ${ }^{I}$ (Research Scholar, Department of Production Engineering, Shree Guru Gobind Singh Institute of Engineering \\ \& Technology, Nanaded, Maharashtra, India) \\ ${ }_{2}^{2}$ (Professor, Department of Production Engineering, Shree Guru Gobind Singh Institute of Engineering \& \\ Technology, Nanaded, Maharashtra, India)
}

\begin{abstract}
To have a effective supply chain it is very much essential to have effective and reliable vendor. It is far more important in case of a service sector. As service is intangible and can only be felt ;hence very much depends on the quality of delivery and after sales activity. Ineffective and unreliable vendor can have a cascading effect in all aspect of service chain resulting customer dissatisfaction. The present study tries to find out the parameter or quality of a vendor that is preferred by telecommunication companies. As telecommunication is a infrastructure service any weak link in the supply chain will have a catastrophic impact on the end user. As vendor is one of the prime component of supply chain its careful selection is of immense importance. There are numerous variables to select a vendor. But to have a quick and effective decisions making these numerous variables are reduced to few factors. In this study the centroid method of factor analysis is used to find four important factors. The study was carried out by interacting executives of around 8 telecom companies amounting to 57 effective data. A broad outline of factors and encompassing variables under each factor were depicted.
\end{abstract}

Keywords - Factor analysis, Supply Chain and Vendor selection,

\section{Introduction}

Telecommunication is a vital infrastructure for growth of economy. Its operational purview expands from basic infrastructure to entertainment. Trade and commerce is unthinkable in the present world without telecom infrastructure. The system is highly technology driven and dynamic in nature. To keep the system operational it is very much essential to have a effective supply chain where availability of components, spares and services should immediate and adequate. In Indian context the procurement (either product or service) is quite cumbersome unlike the developed economy. Hence to select a vendor or to outsource a service a company has to consider and evaluate many parameters which sometimes overlap and make the process confusing. Maggie C.Y. Tam, V.M. Rao Tummala[1] has put forth 19 different parameter for a vendor selection process while studying the Hong-Kong telecom sector encompassing them into thee primary parameters i.e Cost,Technical Capability and After Sales Service.; Sanjay Kumar et.al[2] while analyzing vendor selection for manufacturing industry suggested that reliability of the vendor, product quality and the vendor experience are the top three problems in the vendor selection. V. R. Pramod, D. K. Banwet [3] has made a study on telecommunication service supply chain of Indian public sector telecom companies using ANP technique and found out a lot of interdependencies of factors in telecom service chain. However because of typical nature of Indian business scenario the researchers attempted to make a comprehensive study of main factors of selecting the vendor for a telecom service provider (Public enterprise as well as private) having pan India operation

\subsection{Definition and Progress of SCM in Telecom Service:}

While running their business of providing telecom service, the service providers usually deal with a number of activities, such as: procurement (both hard ware and soft ware), service operation(which includes installation), warehouse management, selling, marketing, and customer servicing(fault diagnosis, repair and rectification) among others. To help them to manage these activities, companies try to automate (i.e placing a system into work) their business processes. Though, independent software and hardware solutions are used for each of the activities; however, in practice, all the activities are highly connected and interdependent. Figure 1 below depicts atypical operation of a telecom service provider. 


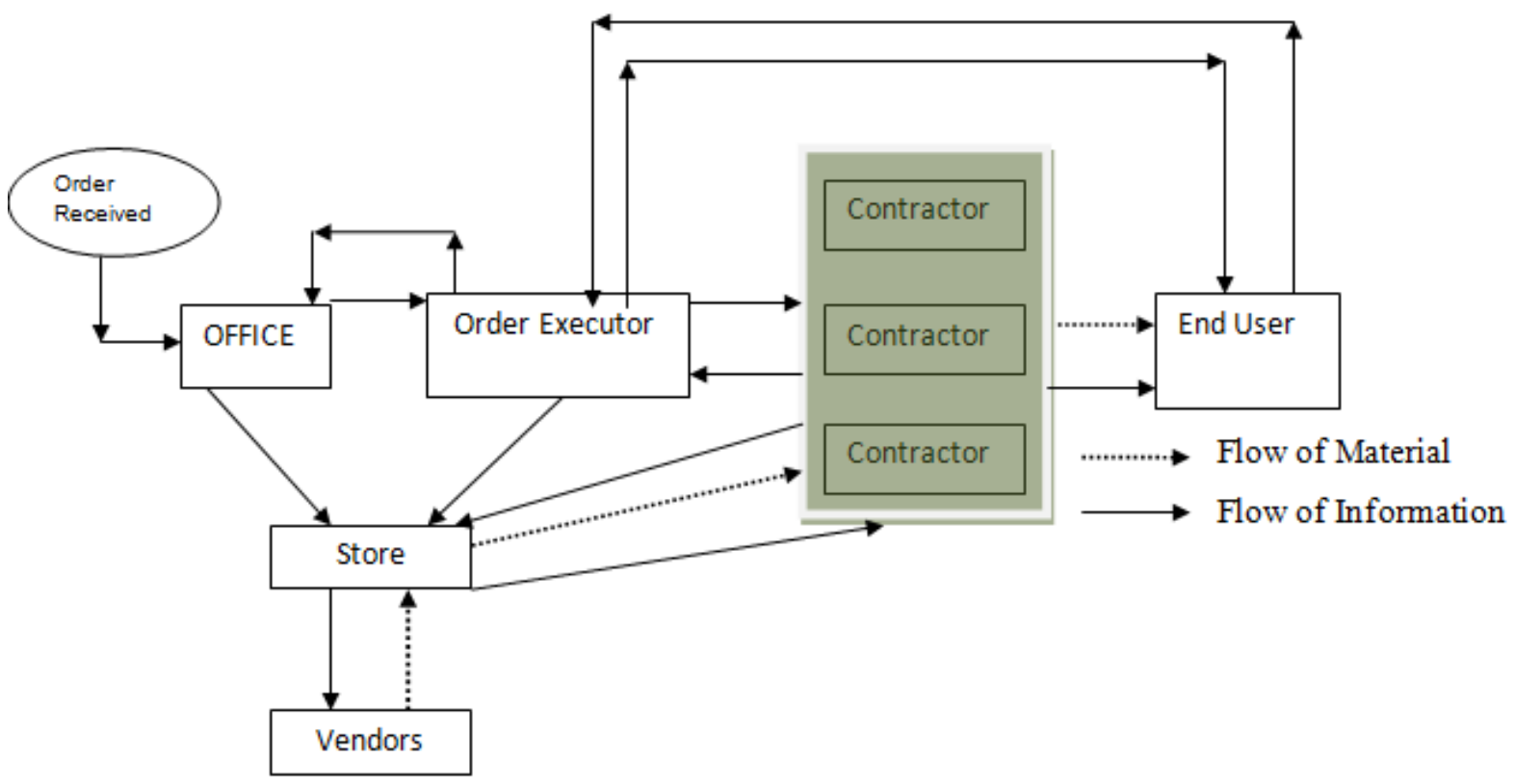

Figure1: Typical operation of a telecom service provider.

If these activities are synthesized then we can enumerate that all activities are having independent entities having their own criterion of operation but fully interdependent on each other in order the system to function. Depicted in table 1 below.

Table:1 Integrating activities of an enterprise

\begin{tabular}{|l|l|l|}
\hline Activities & Solution & Integration \\
\hline Procurement / Storing / Delivery & ERP-Purchasing & $\begin{array}{l}\text { Supply Chain Management } \\
\text { with Decision Support }\end{array}$ \\
\cline { 1 - 2 } $\begin{array}{l}\text { Operation / Technical Support / } \\
\text { Customer Service }\end{array}$ & Logictics and CRM & System \\
\hline Accounting / Marketing & Accounting / IT / CRM & \\
\hline
\end{tabular}

To integrate many of them in a single process is the task of the Supply Chain Management (SCM). SCM is a complex process which includes a number of interrelated activities such as: negotiating with suppliers for input materials, competing for customer orders, managing inventory, scheduling the operation(installation and Service), and delivering goods to customers.

It is probably not possible to trace when the term SCM appeared first and its original definition. The concepts of SCM have been practised by companies since the early $20^{\text {th }}$ century, first discussed in the literature back in the 1950s [J. W. Forrester] [4], and the term itself appeared in publications in the 1970s[J.F. Burns and B.D. Sivazlian ][5]. In the 1980s, the idea to automate SCM business processes became widespread, however, the experts treated every entity in the supply chain as a standalone process isolated from the rest. Many related works in the late 1990s still concentrated only on solving tasks in separate subareas [F. Cheng, M. Ettl, and G Lin.][6], [ J. Hu and P. Wellman] [7] omitting a number of key parameters and constraints, such as temporal and capacity constraints[M. Babaioff and W. E. Walsh] [8],[ M. Babaioff and N. Nissan ][9], W. [E. Walsh and M. P. Wellman ][10]. It is only at the turn of the century when researchers raised the issue of dynamics of the SCM problem domain [Swaminathan et al., 1998][11], and started to look at the SCM as an integrated process that faces constraints [Sun and Sadeh, 2004][12].

With the advent of the World Wide Web, electronic trading systems have become extremely popular in the last decade. After such basic models as e-Shops and e-Procurement, e-Marketplaces have emerged to integrate all business entities (suppliers, customers, partners, trading agents, competitors, etc.) within one global electronic environment [Ghenniwa et al., 2006][13]. These newly established economic institutes are dynamic, rapidly growing and changing. When participating in them, enterprises can no longer rely on static business strategies. They have to be able to cope with the uncertain conditions of these environments.

New system architectures have been proposed recently [Wang et al., 2008][14] to support participation in e-Commerce, [Sadeh-Koniecpol et al., 2003][15], [Goodwin et al., 1999][16]. Most researchers would agree that the architecture of a modern SCM DSS has to be agile in order to cope with dynamics of electronic markets, as well as easy reconfigurable so as to be Multi-Agent Approach to Developing Dynamic SCM Decision 
Support Systems able to adapt to the needs of various businesses and support protocols of different trading environments. The multi-agent approach has proved to be the most suitable to meet these requirements [Jennings and Wooldridge, 1998][17], [He et al., 2003a][18], [Chaib-draa and Muller, 2006][19], [Wang and Fang, 2007][20]. The following sections discuss the latest research in designing modern DSS for eCommerce and SCM in particular.

\subsection{SCM for Telecommunication Service Provider}

Telecommunication markets are saturated. Competition is fierce. And the economy is sluggish. Companies spent a fortune bidding for Telecom licenses and developing new services, only to find that consumer uptake of new services is slow. To meet these challenges and create sustainable value, one need to keep tight control of every aspect of its operations, the specific needs of the telecommunications industry:

- Introduce new products to meet changing demands

- Develop smart delivery strategies based on complete information and powerful, proven

Capabilities

- Find the right balance between maximizing product availability and minimizing costs

In addition, one must have ability to meet demand, slashes costs and inventory levels, and increases the competitiveness.

\subsection{Key Areas}

\subsubsection{Supply Chain Sketching}

Effective, flexible planning is essential in the fast-moving telecommunications industry. This include

- Create detailed plans and forecasts for supply and demand, distribution, production, and

Transportation

- Make better decisions based on comprehensive historical and point-of-sale data

- Involve a range of internal and external organizations in your decision making

- Optimize the manufacture of bundles, such as cell phones with accessories

\subsubsection{Supply Chain Relationship}

This is to collaborate with your suppliers and partners more closely and effectively than ever before, delivering unprecedented flexibility and responsiveness across the extended supply chain. \{Product replenishment - vendor-managed inventory; supplier-managed inventory; or collaborative planning, forecasting, and replenishment (CPFR)\}.

\subsubsection{Supply Chain Coordination}

To track and monitor events at every stage of the logistics cycle. Problems are reported immediately and can be dealt with immediately. Performance management functions provide you with key figures that allow you to evaluate and streamline your supply chain on all levels.

\subsubsection{Supply Chain Execution}

Warehouse and materials management capabilities to enable the supply chain function smoothly from procurement and storage to order picking and shipping thereby facilitating a holistic integrated SCM with reasonable flexibility.

\subsection{Backward and Forward Integration}

The better the IT solutions mesh with each other, the more value they add to the business e.g. CRM for selling activities and Supplier Relationship Management for purchasing activities. End to end integration also encompasses other important processes for telecommunication companies - order management, coordination, and fulfillment tasks relating to both customer-driven and network-driven scenarios. These tasks range from installing services and resolving customer-reported problems to installing network infrastructure and performing maintenance and troubleshooting functions.

By optimizing and strengthening processes throughout supply network, the company should be able you to launch new physical products with maximum efficiency, meet unpredictable demand, and thrive in a highly competitive business environment 


\subsection{Additional Parameters of Good Supply Chain 1.5.1 Control of Costs}

Can be achieved by efficient order processing, effective inter enterprise collaboration, lower inventory levels, and reduced capital expenditures.

\subsubsection{Revenue Generation}

By making company planning more accurate, improving product availability and thereby achieving match of supply to demand. As a result, customer satisfaction increases and company revenues rise.

\subsubsection{Risk Minimization}

With global visibility that puts the company firmly in the driver's seat and gives the total control of enterprise's supply chain. By enabling adaptive supply networks and mutually profitable collaboration, it lets the organization react much more rapidly to change and reduces the risk that comes with sudden change.

\section{Objective of Study}

With the aforementioned back ground this research tries to find out the potential area of consideration for before one starts evaluating a vendor or a supplier or a service provider. The research took into consideration 14 different parameters as potential area of strength of a vendor to typically serve the telecom sector. As this is a technology management driven service, factors related to technology, operation, after sales service, billing \& finance and human resource aspect were taken into consideration. The aim was to find out factors which an end user considers to be more important to streamline its operation.

\section{Methodology}

The study was carried out by using questionnaire. Since the study was qualitative nature, the respondents were asked to just give preference about the quality they expect from a potential vendor/supplier/service provider.

The frame work of study is as follows

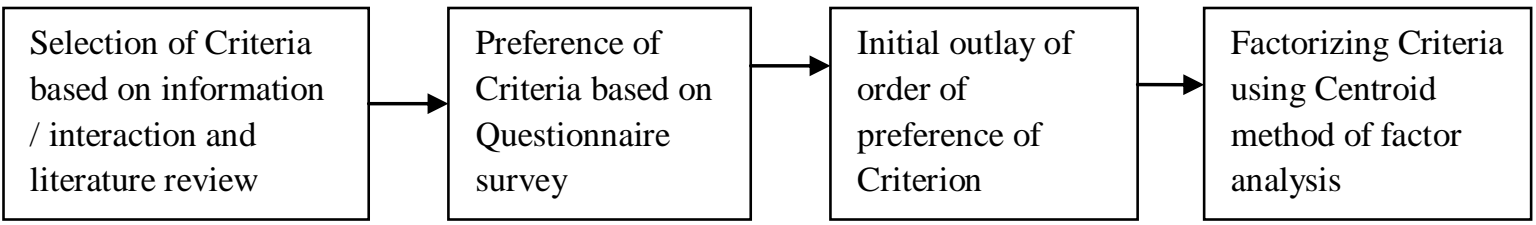

Figure.2 The study frame work

The study was carried out by questionnaire survey as well as personal interview with executives of 8(Eight) telecom service provider having pan India operation. In all total more than 100 executives dealing with procurement, purchase and outsourcing were contacted. However in all the researcher received 57 relevant data from different respondents.

\subsection{Factor Analysis}

In real life application there would be number of independent variable those come into picture while predicting any response. Due to this type of excessive independent variables the problem of prediction becomes multifold due to

i. Increased computational time to get solution

ii. A lot of time in collecting the data and making the collection expensive

iii. Presence of redundant independent variables

iv. Difficulty in making inference

Factor analysis is a handy tool in clubbing down too many parameters into few parameters so that an effective collection, analysis and interpretation of data can be made. Theoretically, the total number of factors in the factor analysis is equal to the total number of input variables. But after factor analysis we can make out some of the insignificant factor $\mathrm{s}$ which can be dropped out. However each factor analysis is based on certain criterion.

For this research centroid method of factor analysis is used. This method maximizes the sum of absolute loading of each factor. In this method the co efficient of the terms in the linear composite of each other will be either +1 or -1 .In this method the respondents and corresponding variables are collected as data. Then for each variable a correlation coefficient for every other variable is obtained in a matrix form. This is followed by reflection of correlation coefficient matrix if required. 
Once reflections are over we get a matrix which is capable of giving us the factor 1.This is done by finding column sum of (each variable) matrix $S_{j}$ and $T$.

$$
\mathrm{T}=\text { Grand total of column total }=\sum \mathrm{S}_{\mathrm{j}(\mathrm{j}=1 \text { ton })}
$$

And for each variable loading factor $\mathrm{L}_{1(\mathrm{j})}=\mathrm{S}_{\mathrm{j}} / \sqrt{ } \mathrm{T}$. The same would be loaded negatively if reflection has been done or it will be taken as it is. These loading are taken as factor 1.In the next step the cross product matrix which consists of product of each pair of coefficient of loading $\left[\mathrm{L}_{1(\mathrm{j})}\right]$ is obtained. Then we try to obtain residual matrix by subtracting the cross product matrix from original correlation coefficient matrix before reflection. This residual matrix will be primary matrix for reflection to get factor 2 .

This iteration will be continued till we get all the desired factors. It means if two factors are required then loading of second residual matrix would be last step. If three factors are required then we go for third iteration with second matrix (i. e first residual matrix) as base. Once all factor loadings are obtained the final computation is done by finding the eigen values as follows( table 2 ).

Table 2.Factor Loadings

\begin{tabular}{|c|c|c|c|c|c|c|c|c|}
\hline \multirow[b]{2}{*}{ Variable } & \multicolumn{7}{|c|}{ Factor } & \multirow{2}{*}{$\begin{array}{l}\text { Communality } \\
\text { (Sum of } \\
\text { Squares of } \\
\text { Row) }\end{array}$} \\
\hline & 1 & 2 & 3 & $\ldots$ & $\mathrm{f}$ & $\ldots$ & $\mathrm{F}$ & \\
\hline $\mathrm{X} 1$ & $\mathrm{~L}_{1}(1)$ & $\mathrm{L}_{2}(1)$ & $\mathrm{L}_{3}(1)$ & $\ldots$ & $\mathrm{L}_{\mathrm{f}}(1)$ & $\ldots$ & $\mathrm{L}_{\mathrm{F}}(1)$ & $\sum \mathrm{L}_{\mathrm{f}}(1)^{2}$ \\
\hline $\mathrm{X} 2$ & $\mathrm{~L}_{1}(2)$ & $\mathrm{L}_{2}(2)$ & $\mathrm{L}_{3}(2)$ & $\ldots$ & $\mathrm{L}_{\mathrm{f}}(2)$ & $\ldots$ & $\mathrm{L}_{\mathrm{F}}(2)$ & $\sum \mathrm{L}_{\mathrm{f}}(2)^{2}$ \\
\hline $\mathrm{X} 3$ & $\mathrm{~L}_{1}(3)$ & $\mathrm{L}_{2}(3)$ & $\mathrm{L}_{3}(3)$ & $\ldots$ & $\mathrm{L}_{\mathrm{f}}(3)$ & $\ldots$ & $\mathrm{L}_{\mathrm{F}}(3)$ & $\sum \mathrm{L}_{\mathrm{f}}(3)^{2}$ \\
\hline . & $\ldots$ & $\ldots$ & $\ldots$ & $\ldots$ & $\ldots$ & $\ldots$ & $\ldots$ & $\ldots$ \\
\hline . & $\ldots$ & $\ldots$ & $\ldots$ & $\ldots$ & $\ldots$ & $\ldots$ & $\ldots$ & $\ldots$ \\
\hline$X_{i}$ & $\mathrm{~L}_{1}(\mathrm{i})$ & $\mathrm{L}_{2}(\mathrm{i})$ & $\mathrm{L}_{3}(\mathrm{i})$ & $\ldots$ & $\mathrm{L}_{\mathrm{f}}(\mathrm{i})$ & $\ldots$ & $\mathrm{L}_{\mathrm{F}}(\mathrm{i})$ & $\sum \mathrm{L}_{\mathrm{f}}(\mathrm{i})^{2}$ \\
\hline$\cdot$ & $\cdots$ & $\cdots$ & $\cdots$ & $\cdots$ & $\cdots$ & $\cdots$ & $\cdots$ & $\cdots$ \\
\hline$\cdot$ & $\ldots$ & $\ldots$ & $\ldots$ & $\cdots$ & $\ldots$ & $\cdots$ & $\ldots$ & . \\
\hline $\mathrm{X}_{\mathrm{n}}$ & $\mathrm{L}_{1}(\mathrm{n})$ & $\mathrm{L}_{2}(\mathrm{n})$ & $\mathrm{L}_{3}(\mathrm{n})$ & $\ldots$ & $\mathrm{L}_{\mathrm{f}}(\mathrm{n})$ & $\ldots$ & $\mathrm{L}_{\mathrm{F}}(\mathrm{n})$ & $\sum \mathrm{L}_{\mathrm{f}}(\mathrm{n})^{2}$ \\
\hline $\begin{array}{l}\text { Eigen } \\
\text { Value }\end{array}$ & $\sum \mathrm{L}_{1}(\mathrm{i})^{2}$ & $\sum \mathrm{L}_{2}(\mathrm{i})^{2}$ & $\sum \mathrm{L}_{3}(\mathrm{i})^{2}$ & $\ldots$ & $\sum \mathrm{L}_{\mathrm{f}}(\mathrm{i})^{2}$ & $\cdots$ & $\sum \mathrm{L}_{\mathrm{F}}(\mathrm{i})^{2}$ & $\sum \sum \mathrm{L}_{\mathrm{f}}(\mathrm{i})^{2}$ \\
\hline
\end{tabular}

Ref: Paneerselvam R , Research Methodology, PHI,(April,2006 Edn.) pp 438[21]

For each factor $(f)$ the following parameters are to be found to get a final reference

Proportion of total variance of the factor $f=$

Eigen Value of Factor $f$

Total Variance(i.e. number of variables $n$ )

Proportion of common variance of the factor $f=$

Eigen Value of Factor $f$

$$
\text { Common Variance(i.e. } \left.\sum \sum \mathrm{L}_{\mathrm{f}}(\mathrm{i})^{2}\right)
$$

\section{The Study}

The study was carried out to get theme of understanding the parameters generally considered by a telecom operator while selecting its vendor. There are as many as 15 parameters prescribed by different researcher and different management practitioner as listed below.

1. 3PL

2. Channel Partner

3. Close partnership with customer

4. Close partnership with supplier

5. EDI

6. e-procurement

7. Few Suppliers(maximum 5)

8. Holding safety stock

9. JIT supply

10. Many suppliers(More than 5)

11. Outsourcing

12. Plan strategically

13. Subcontracting 
14. Use of external consultant

15. Vertical Integration

The researcher requested the persons those who are in the process of procurement, out sourcing and vendor selection activity of any telecom service provider to give ratings and preference to various factors as listed above. The telecom service provider those who are in all aspect of telecom service (i.e. landline, cellular, DTH and broadband) are considered for thesurvey.

Initial analysis of study indicated that the factor like EDI(Electronic Data Input) has no weightage. It means EDI does not carry any specific significance as criteria of selecting a vendor. And careful observation of the data indicate that many parameters are having less than $10 \%$ weightage. Many are in the weightage of $16 \%$ to 35\%.Factors like holding safety stock and close partnership with supplier are having maximum weightage(Figure 3). Further interaction with these executives indicated that they felt many parameters were being overlapped. So the researcher tried to find out important five factors which are of prime importance to select a vendor.

The research was conducted by interacting with 57 respondents of 8 different telecom companies. The initial data was as follows (Table 3). The factor of $\mathrm{X}_{1}$ was discarded as preliminary observation indicated that it has zero weightage. In all now there are 14 factors and out of that five are to be found out in the order of

Figure 3 Preliminary View Regarding Factors

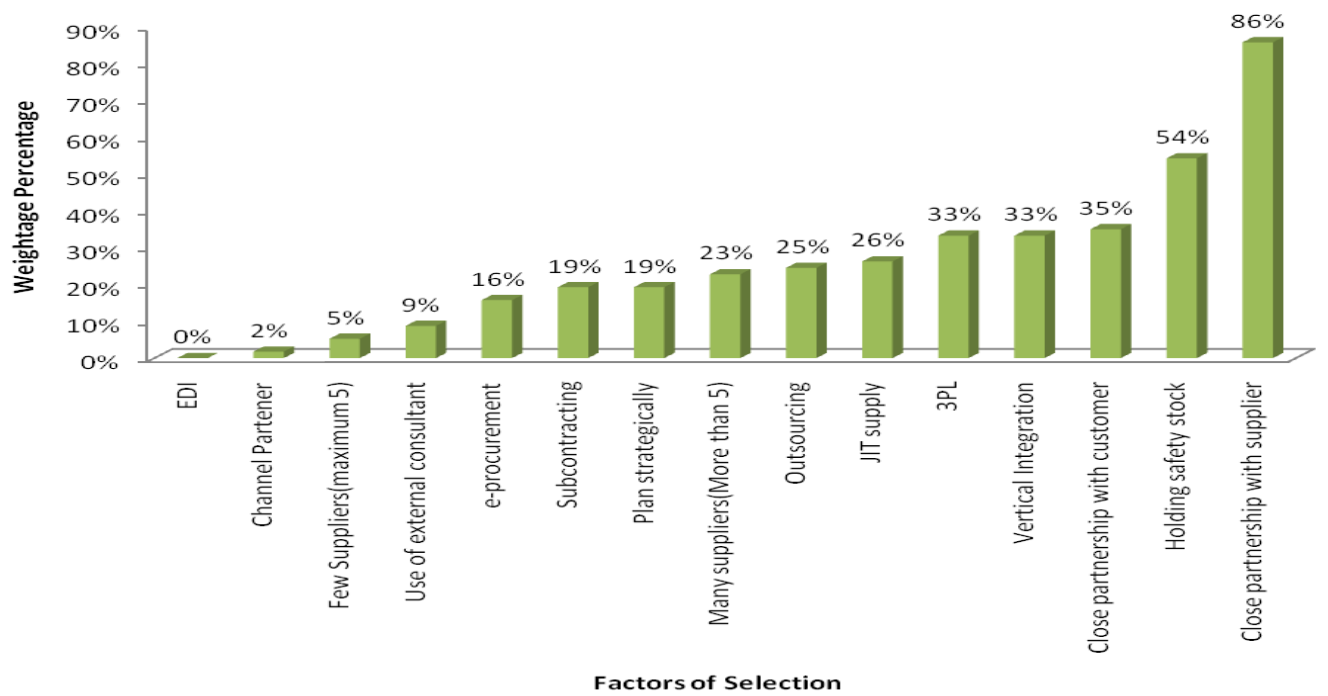

weightage i.e preference.

Table 3 Respondents (Telecom Operators' Opinion about parameters for selecting a vendor)

\begin{tabular}{|c|c|c|c|c|c|c|c|c|c|c|c|c|c|c|}
\hline \multirow{3}{*}{$\begin{array}{l}\text { Re } \\
\text { sp } \\
\text { on } \\
\text { de } \\
\text { nts }\end{array}$} & \multicolumn{14}{|c|}{ Factors } \\
\hline & 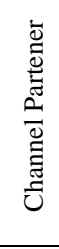 & 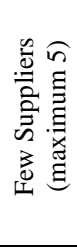 & 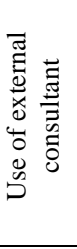 & 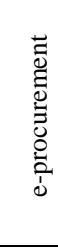 & 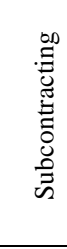 & 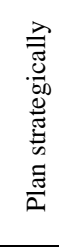 & 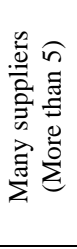 & $\begin{array}{l}0 \\
.0 \\
0 \\
0 \\
0 \\
0 \\
0 \\
0 \\
0\end{array}$ & 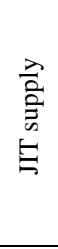 & $\vec{m}$ & 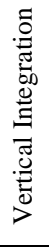 & 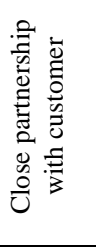 & 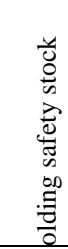 & 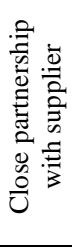 \\
\hline & & & & & & & & & $\mathrm{X} 1$ & & $\mathrm{X} 1$ & & & $\mathrm{X} 1$ \\
\hline & $\mathrm{X} 2$ & $\mathrm{X} 3$ & $\mathrm{X} 4$ & $\mathrm{X} 5$ & $\mathrm{X} 6$ & $\mathrm{X} 7$ & $\mathrm{X} 8$ & $\mathrm{X} 9$ & 0 & $\mathrm{X} 11$ & 2 & $\mathrm{X} 12$ & $\mathrm{X} 14$ & 5 \\
\hline 1 & 0 & 0 & 0 & 0 & 0 & 0 & 0 & 0 & 0 & 0 & 0 & 0 & 0 & 10 \\
\hline 2 & 0 & 0 & 0 & 0 & 0 & 0 & 6 & 1 & 0 & 6 & 6 & 3 & 7 & 10 \\
\hline 3 & 0 & 1 & 3 & 3 & 3 & 6 & 3 & 4 & 1 & 4 & 9 & 6 & 9 & 6 \\
\hline 4 & 0 & 2 & 0 & 0 & 2 & 4 & 0 & 6 & 4 & 2 & 0 & 0 & 10 & 8 \\
\hline 5 & 0 & 0 & 4 & 2 & 6 & 4 & 8 & 4 & 2 & 2 & 2 & 6 & 4 & 8 \\
\hline 6 & 0 & 0 & 0 & 0 & 3 & 3 & 0 & 3 & 0 & 0 & 3 & 10 & 5 & 10 \\
\hline 7 & 0 & 1 & 1 & 4 & 2 & 1 & 1 & 1 & 4 & 0 & 1 & 3 & 1 & 7 \\
\hline 8 & 1 & 0 & 0 & 1 & 1 & 1 & 0 & 2 & 5 & 5 & 3 & 2 & 5 & 10 \\
\hline
\end{tabular}


The foctors were found out by centriod method of in the form of five iteration. The intial correlation matrix is as follows. Futher iterations were made out of this basic correlation matrix (Table 4).

Table 4 Initial Correlation Matrix.

\begin{tabular}{|r|r|r|r|r|r|r|r|r|r|r|r|r|r|r|}
\cline { 2 - 16 } \multicolumn{1}{c|}{} & $\mathrm{X} 2$ & $\mathrm{X} 3$ & $\mathrm{X} 4$ & $\mathrm{X} 5$ & $\mathrm{X} 6$ & $\mathrm{X} 7$ & $\mathrm{X} 8$ & $\mathrm{X} 9$ & $\mathrm{X} 10$ & $\mathrm{X} 11$ & $\mathrm{X} 12$ & $\mathrm{X} 13$ & $\mathrm{X} 14$ & $\mathrm{X} 15$ \\
\hline $\mathrm{X} 2$ & 1 & 0 & 0 & 0 & 0 & 0 & 0 & 0 & 1 & 0 & 0 & 0 & 0 & 0 \\
\hline $\mathrm{X} 3$ & 0 & 1 & 0 & 0 & 0 & 1 & 0 & 1 & 0 & 0 & 0 & 0 & 1 & -1 \\
\hline $\mathrm{X} 4$ & 0 & 0 & 1 & 1 & 1 & 1 & 1 & 0 & 0 & 0 & 0 & 0 & 0 & -1 \\
\hline $\mathrm{X} 5$ & 0 & 0 & 1 & 1 & 0 & 0 & 0 & 0 & 1 & 0 & 0 & 0 & 0 & -1 \\
\hline $\mathrm{X} 6$ & 0 & 0 & 1 & 0 & 1 & 1 & 0 & 1 & 0 & 0 & 0 & 1 & 0 & 0 \\
\hline $\mathrm{X} 7$ & 0 & 1 & 1 & 0 & 1 & 1 & 0 & 1 & 0 & 0 & 0 & 0 & 1 & -1 \\
\hline $\mathrm{X} 8$ & 0 & 0 & 1 & 0 & 0 & 0 & 1 & 0 & 0 & 0 & 0 & 0 & 0 & 0 \\
\hline $\mathrm{X} 9$ & 0 & 1 & 0 & 0 & 1 & 1 & 0 & 1 & 0 & 0 & 0 & 0 & 1 & 0 \\
\hline $\mathrm{X} 10$ & 1 & 0 & 0 & 1 & 0 & 0 & 0 & 0 & 1 & 0 & 0 & 0 & 0 & 0 \\
\hline $\mathrm{X} 11$ & 0 & 0 & 0 & 0 & 0 & 0 & 0 & 0 & 0 & 1 & 1 & 0 & 1 & 0 \\
\hline $\mathrm{X} 12$ & 0 & 0 & 0 & 0 & 0 & 0 & 0 & 0 & 0 & 1 & 1 & 0 & 0 & 0 \\
\hline $\mathrm{X} 13$ & 0 & 0 & 0 & 0 & 1 & 0 & 0 & 0 & 0 & 0 & 0 & 1 & 0 & 0 \\
\hline $\mathrm{X} 14$ & 0 & 1 & 0 & 0 & 0 & 1 & 0 & 1 & 0 & 1 & 0 & 0 & 1 & 0 \\
\hline $\mathrm{X} 15$ & 0 & -1 & -1 & -1 & 0 & -1 & 0 & 0 & 0 & 0 & 0 & 0 & 0 & 1 \\
\hline
\end{tabular}

The initial Correlation Matrix was iterated for five times and the final outcome is as follows (Table 5).

Table 5. Final iteration to find five factors.

\begin{tabular}{|c|c|c|c|c|c|c|}
\hline \multirow{2}{*}{ Variables } & \multicolumn{5}{|c|}{ Factor } & \multirow{2}{*}{ Communality(h2) } \\
\hline & 1.00 & 2.00 & 3.00 & 4.00 & 5.00 & \\
\hline $\mathrm{X} 2$ & -0.45 & 0.42 & -0.44 & 0.49 & 0.39 & 0.96 \\
\hline $\mathrm{X} 3$ & -0.64 & -0.92 & -1.07 & -1.48 & -1.75 & 7.65 \\
\hline $\mathrm{X} 4$ & 0.68 & -0.56 & -0.46 & 0.50 & -0.42 & 1.41 \\
\hline $\mathrm{X} 5$ & -0.55 & -0.85 & -0.83 & -0.99 & -1.28 & 4.32 \\
\hline X6 & 0.69 & -0.53 & 0.45 & 0.48 & -0.58 & 1.51 \\
\hline $\mathrm{X7}$ & 0.79 & 0.53 & -0.64 & -0.62 & -0.65 & 2.13 \\
\hline $\mathrm{X} 8$ & 0.56 & -0.42 & -0.32 & -0.41 & 0.60 & 1.12 \\
\hline $\mathrm{X} 9$ & 0.67 & 0.61 & -0.60 & -0.61 & -0.63 & 1.94 \\
\hline $\mathrm{X} 10$ & -0.55 & -0.61 & 0.80 & -0.67 & -0.72 & 2.28 \\
\hline $\mathrm{X} 11$ & -0.46 & 0.73 & 0.65 & 0.86 & -1.26 & 3.47 \\
\hline $\mathrm{X} 12$ & 0.54 & -0.48 & -0.54 & -0.65 & -0.87 & 1.99 \\
\hline $\mathrm{X} 13$ & 0.51 & -0.31 & -0.29 & -0.32 & -0.47 & 0.77 \\
\hline $\mathrm{X} 14$ & 0.57 & 0.63 & 0.58 & -0.72 & -0.45 & 1.78 \\
\hline X15 & -0.76 & -0.62 & -0.87 & -1.09 & -1.61 & 5.50 \\
\hline Eigen Cvalue & 5.21 & 5.16 & 5.82 & 8.24 & 12.40 & 36.83 \\
\hline
\end{tabular}

Prop of Total

$\begin{array}{llllll}\text { Var } & 0.371826 & 0.368853 & 0.4157 & 0.5884 & 0.886\end{array}$

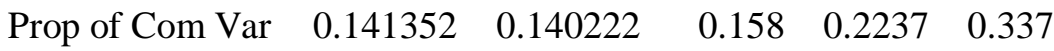




\section{Analysis}

We could infer from our analysis that all the variables are accommodated in four factors. It means in four
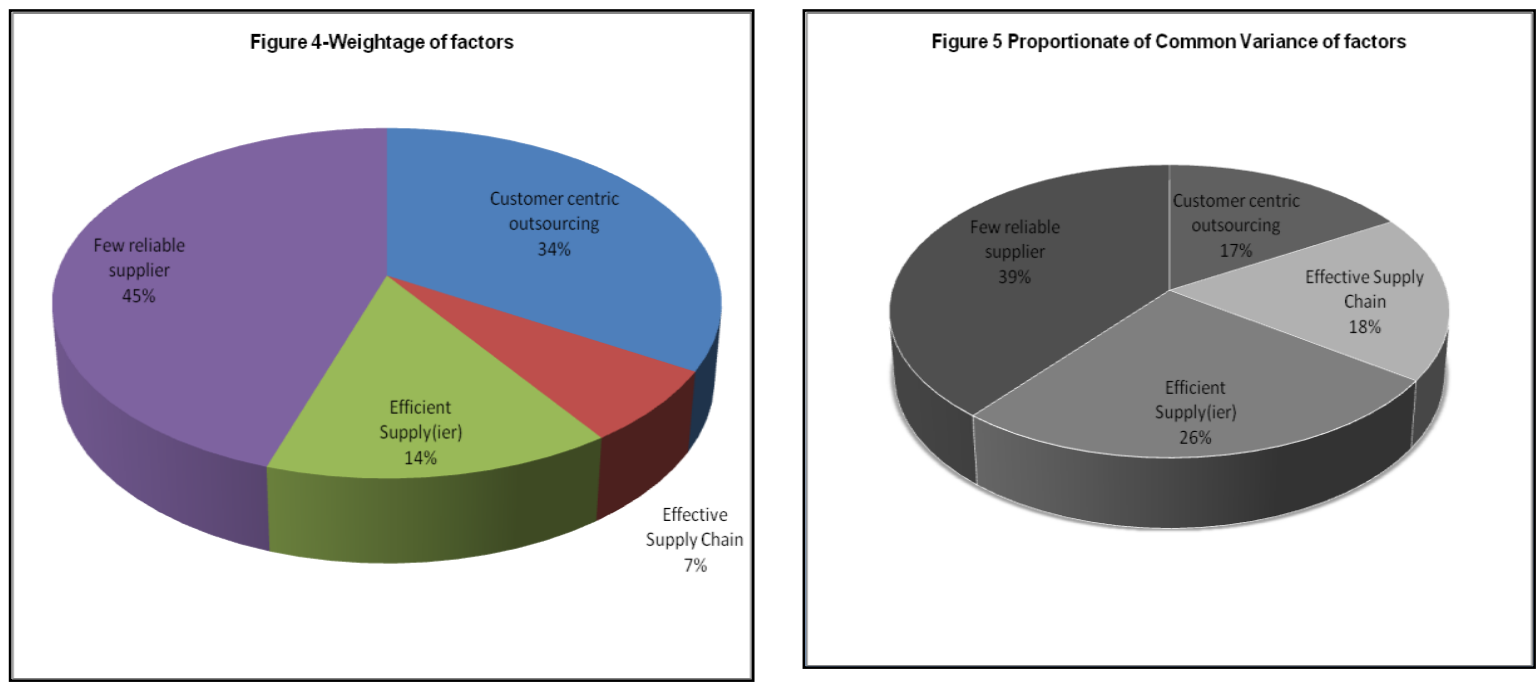

different criteria are good enough to decide the capability of a vendor to a telecommunication service provider in India. The weighatge to different factors are depicted in figure.4.The weightage varies from few reliable supplier as prime factor in selecting a vendor with effective supply chain being least weightage. Hence while evaluating or recommending or selecting the vendor for a telecom service provider operating in India the prime concern should be about consisting the criteria to few reliable vendors.Any outsourcing should be final customer concentric. Supplier should be efficient to supply with a effective supply chain mechanism(i.e. transport etc). Looking at the aspect of common variance (Figure .5) it can be infered that the most preferred factor(i.e few reliable supplier) accounts for maximum common variance of all factors. This is followed by the factor of efficient supply (26\% of common variance).The consumer cncentric ousourcing and effective supply chain accounts for $17 \%$ and $18 \%$ of common variance. This indicates that effective supplly is very relative issue and can not be univrsalised to a certain extent.

\section{Conclusion}

In selecting a vendor for a telecommunication system of Indian operation there are around 15 parameters.As depicted in table 5 all these may be scaled down to four factors as perceived by the procurment authorities of Indian telecommunication service provider.

Table 6 Prime Factors of Vendor Selection for Indian Telecommunication Service Provider

\begin{tabular}{|c|c|c|}
\hline Sl.No & Factor & Variables \\
\hline \multirow{6}{*}{1} & \multirow[t]{6}{*}{ Customer centric outsourcing } & Use of external consultant \\
\hline & & Subcontracting \\
\hline & & Plan strategically \\
\hline & & Many suppliers(More than 5) \\
\hline & & Outsourcing \\
\hline & & Close partnership with customer \\
\hline \multirow{5}{*}{2} & \multirow[t]{5}{*}{ Few reliable supplier } & Few Suppliers(maximum 5) \\
\hline & & e-procurement \\
\hline & & 3PL \\
\hline & & Vertical Integration \\
\hline & & Close partnership with supplier \\
\hline \multirow{2}{*}{3} & \multirow[t]{2}{*}{ Efficient Supply(ier) } & Channel Partner \\
\hline & & Holding safety stock \\
\hline 4 & Effective Supply Chain & JIT supply \\
\hline
\end{tabular}

The broad analysis of these four factors can lead to make a detailed analysis of each variables for evaluating a vendor. 


\section{References:}

[1] Maggie C.Y. Tama, V.M. Rao Tummalab; An application of the AHP in vendor selection of atelecommunications system ;International Jouirnal of Management Science;Omega 29 (2001) (171-182)

[2] Sanjay Kumar, Neeraj Parashar, Abid Haleem; Analytical Hierarchy Process Applied to Vendor Selection Problem: Small Scale, Medium Scale and Large Scale Industries Business Intelligence Journal - August, 2009 Vol. 2 No. 2(pp 355-362)

[3] V.R Pramod and D.K Banwet: Analytic Network Process Analysis of an Indian Telecommunication Service Supply Chain: A Case Study ;Service Science 2(4), pp. 281-293,

[4] J. W. Forrester. Industrial dynamics-a major breakthrough for decision makers. Harvard Business Review, 36(4):37-66, 1958

[5] J.F. Burns and B.D. Sivazlian. Dynamic analysis of multi-echelon supply systems. Computers and Industrial Engineering, 2:18193, 1978.

[6] F. Cheng, M. Ettl, and G Lin. Inventory-service optimization in configure-to-order systems. Technical Report RC 21781, IBM, 2001 .

[7] J. Hu and P. Wellman. Multiagent reinforcement learning: Theoretical framework and an algorithm. In the Fifteenth International Conference on Machine learning, pages 242-250, 1998.

[8] M. Babaioff and W. E. Walsh. Incentive-compatible, budget-balanced, yet highly efficient auctions for supply chain formation. Decision Support Systems, 39(1):123 - 149, 2005. doi: 10.1016/j.dss.2004.08.008.

[9] M. Babaioff and N. Nissan. Concurrent auctions across the supply chain. In proceedings of the third ACM conference on electronic commerce, pages 1-20, Tampa, Florida, USA, 2001.

[10] W. E. Walsh and M. P. Wellman. Decentralized supply chain formation: a market protocol and competitive equilibrium analysis. Journal of Artificial Intelligence Research, 19:513 - 567, 2003

[11] J.M. Swaminathan, S.F. Smith, and N.M. Sadeh. Modeling supply chain dynamics: A multiagent approach. Decision Science, 29(30):607-632, 1998 .

[12] J. Sun and N.M. Sadeh. Coordinating multi-attribute reverse auctions subjects to finite capacity considerations. Technical report CMU-ISRI-03-105, Carnegie Mellon University, 2004.

[13] H. Ghenniwa, J. Dang, M. Huhns, and W. Shen. Multiagent-Bbased Supply Chain Management, chapter eMarketPlace Model: An Architecture for Collaborative Supply Chain Management and Integration,. Springer-Verlag Berlin Heidelberg, pages $29-622006$.

[14] M. Wang, J. Liu, H. Wang, W. K. Cheung, and X. Xie. On-demand e-supply chain integration: A multi-agent constraint-based approach. Expert Systems with Applications: An International Journal, 34(4):2683-2692, 2008.

[15] N. Sadeh-Koniecpol, D. Hildum, and D. Kjenstad. Agent-based e-supply chain decision .Journal of Organizational Computing and Electronic Commerce, 13(3):225-242, 2003.

[16] R. Goodwin, P. Keskinocak, S. Murthy, F. Wu, and R. Akkiraju. Intelligent decision support for the e-supply chain. In Artificial Intelligence for Electronic Commerce, AAAI Workshop 99, pages 770-773, 1999.

[17] N.R. Jennings and M.J. Wooldridge. Agent Technology: Foundations, Applications, and Markets. Springer, 1998.

[18] M. He, N. R. Jennings, and H. Leung. On agent-mediated electronic commerce. IEEE Transactions on Knowledge and Data Engineering, 15:985-1003, 2003a. doi: 10. 1.1.114.4818. URL http://citeseerx.ist.psu.edu/viewdoc/summary? doi=10.1.1.114.4818.

[19] B. Chaib-draa and J.P. Muller. Multiagent-Based Supply Chain Management, volume 28 of Studies in Computational Intelligence. Springer-Verlag Berlin Heidelberg, 2006.

[20] Y. Wang and L. Fang. Design of an intelligent agent-based supply chain simulation system.Systems, Man and Cybernetics, page 1836 1841, 2007. doi: 10.1109/ICSMC.2007. 4414189

[21] Paneerselvam R, Research Methodology, PHI,(April,2006 Edn.) 